Esta revista forma parte del acervo de la Biblioteca Jurídica Virtual del Instituto de Investigaciones Jurídicas de la UNAM

\title{
El nuevo derecho internacional privado chino: cercanía o lejanía con el derecho latinoamericano sobre la materia
}

\author{
The New Chinese Private International Law: \\ Closeness or Distance with Latin American \\ Law on the Subject
}

\author{
Le nouveau droit international privé \\ chinois: proche ou lointain du droit \\ latinoaméricain sur le sujet
}

José Luis Marín Fuentes*

\begin{abstract}
SUMARIO: I. Introducción. II. Apuntes sobre el derecho internacional privado. III. China y la evolución de su derecho. IV. El derecho internacional privado en Latinoamérica. V. El derecho internacional privado en China. VI. Ámbito de aplicación material de la nueva Ley China. VII. Reflexiones finales. VIII. Bibliografía.
\end{abstract}

* Profesor de Derecho internacional privado y Contratos internacionales de la Universidad de Medellín. Correo electrónico:jlmarin@udem.edu.co.

Artículo recibido el 17 de enero de 2017 Aprobado para publicación el 25 de septiembre de 2017 
RESUMEN: El presente ejercicio pretende llevar a cabo un estudio aproximado y tangencial sobre las normas contenidas en la nueva ley china referentes a las leyes aplicables a las relaciones civiles con elementos de extranjería y las diferentes leyes que regulan la materia en algunos de los países que forman parte del bloque latinoamericano, con ello se busca definir en qué aspectos presentan coincidencias y en cuáles divergencias; todo ello con miras a entender mejor cómo se está regulando el derecho internacional privado en estas dos partes del mundo y la proximidad o la distancia entre los mismos.

Palabras clave: conflicto de leyes, residencia habitual, orden público, vínculos más estrechos, parte débil.

ABSTRACT: This exercise aims to conduct a tangential study over the rules contained in the new Chinese law on the Laws applicable to foreign-related civil relations and the different laws governing the matter in some of the countries that are part of the Latin American bloc, looking to see what aspects matches and which doesn't; all that with the purpose of better understand how it is regulating private international law in these two parts of the world and what are the proximity or distance existing between them.

Key words: conflict of laws, habitual residence, public order, closely connected law, weaker party.

RÉSUMÉ: Cet exercice vise à faire une étude approximative et tangentiel aux règles contenues dans la nouvelle Loi Chinoise sur les lois applicables aux relations civiles avec des éléments étrangers et des lois différentes régissant la matière dans certains des pays qui font partie du bloc de l'Amérique Latine, cherchant ainsi à voir quels aspects sont présentés des divergences et des coïncidences; tout en vue de mieux comprendre comment est réglementé le droit international privé dans ces deux parties du monde et de la proximité ou de distance entre eux. Mots-clés: conflit de lois, la residence habituelle, l’ordre public, loi etroitement lie, partie la plus faible. 
Esta revista forma parte del acervo de la Biblioteca Jurídica Virtual del Instituto de Investigaciones Jurídicas de la UNAM

\section{INTRODUCCIÓN}

Para nadie es un secreto la importancia cada vez mayor que va adquiriendo China en nuestra vida diaria; desde el momento en el que comenzó a despertar el denominado "gigante" o "tigre asiático", sus acciones han venido permeando lentamente nuestras vidas y nuestro acontecer diario, sin importar en qué lugar nos hallemos; de igual forma ha sucedido con su ordenamiento jurídico, el cual se ha adaptado de manera progresiva a los modelos occidentales, quizás con el propósito de acceder a una mejor comprensión sobre cómo se regulan allí las cuestiones jurídicas, para, de esta forma, acoplarse a esa nueva tendencia mundial que va marcando gradualmente la globalización en cada uno de sus aspectos.

De esta manera, el presente ensayo pretende llevar a cabo un breve análisis de las normas que regulan las cuestiones del derecho internacional privado en dos ámbitos territoriales no sólo muy distantes sino culturalmente opuestos, pero con ciertos vínculos que ameritan la realización del mismo; para ello partiremos de las siguientes dos interrogantes: ¿es posible hablar de una cercanía entre el ordenamiento jurídico chino en materia de derecho internacional privado, y aquellos otros que abarcan el espectro judicial latinoamericano? y ¿puede hablarse de una preeminencia de uno de esos derechos sobre el otro o los otros?

Ahora bien, frente a tales preguntas, la cuestión no es tarea fácil, ya que, como más adelante se podrá observar, el objeto que aquí se estudia en algunos aspectos no permite hacer dicho acercamiento, toda vez que si bien se trata de abordar principios que son estándar a muchas relaciones jurídicas sin importar el lugar donde se lleven a cabo y quiénes la realicen; en el caso chino existe una cuestión cultural que es muy difícil de conciliar con la que se vive en Latinoamérica; sin embargo, existen otros puntos de acercamiento y éstos tienen que ver con la aplicabilidad de las normas de conflicto de leyes, donde una de las particularidades de las mismas es su neutralidad con relación al lugar en el que han de aplicarse y frente a las personas para quienes serán efectivas.

Por ello, en un primer lugar se tratará de abordar los orígenes del derecho internacional privado como ciencia jurídica y luego se estudiará la influencia que éste ha tenido no sólo en América Latina, sino también en el 
Esta revista forma parte del acervo de la Biblioteca Jurídica Virtual del Instituto de Investigaciones Jurídicas de la UNAM

territorio dominado por la cultura china, esto es, el continental y el insular. En este sentido se analizará el desarrollo de la materia en cada uno de estos espacios y la forma en la que se ha implementado al interior de los diferentes ordenamientos jurídicos.

En ese sentido, es importante señalar que Latinoamérica, a diferencia de China, no se estructura como un único país, sino que está compuesto por Estados con diferentes sistemas jurídicos, de los cuales unos comparten cierta tradición y los otros no; de ahí que lo que se busca es, esencialmente, hacer un paralelo entre ambas tradiciones y apreciar, desde el punto de vista jurídico, los diferentes matices que sobre la materia se presentan.

Por eso es oportuno indicar que más que tratar de hacer un estudio de cada sistema en común, lo que se pretende es analizar aquellas similitudes o divergencias que éstos pueden presentar respecto a la aplicación de tal clase de normas, es decir, las de conflicto de leyes en sus respectivos territorios. De ahí que nuestro estudio se centrará principalmente en la nueva Ley China sobre las Leyes Aplicables a las Relaciones Civiles con Elementos de Extranjería de 2010, así como en las diferentes normativas que al respecto existen en el continente latinoamericano, tratando con ello de comprender aquellas cuestiones que tienen el mismo manejo, así como aquellas que son tratadas de manera diferente.

\section{APUNTES SOBRE EL DERECHO INTERNACIONAL PRIVADO}

A pesar de que el derecho romano como producto histórico es concomitante con el nacimiento, estructuración y decadencia de Roma, y fue vigente hasta la muerte de su emperador Justiniano, no por ello se puede afirmar que ése fuera su epílogo; al contrario, después de permanecer varios siglos en el anonimato, soportando el frío y la oscuridad de un monasterio, reaparece a finales del siglo XI con la escuela de Bolonia, donde surge lo que se conoce como la tradición romanista, la cual llega hasta nuestros días ${ }^{1}$ y se desplaza a todos los rincones del planeta.

1 Dupla Marín, María Teresa, "La recepción del derecho romano en el movimiento de unificación del derecho privado y la Constitución europea”, septiembre-noviembre de 2016, disponible en: http: / ruc.udc.es/bitstream/2183/2225/1/AD-7-14.pdf. 
Esta revista forma parte del acervo de la Biblioteca Jurídica Virtual del Instituto de Investigaciones Jurídicas de la UNAM

No es una cuestión fácil establecer con exactitud el punto de partida de la ciencia del derecho internacional tal como hoy la conocemos; se estima que sus primeros análisis se dieron a finales del siglo XII, de la mano de insignes académicos como Inerio, Acurssio, Bartolo de Sassoferrato, Baldo de Ubaldis, Balduinus y Odofredus, pertenecientes a las Escuelas de los Glosadores y de los Postglosadores, quienes comienzan a analizar la separación entre la determinación del tribunal competente y la selección del derecho aplicable; esto es, la distinción entre el forum y el ius. Igualmente se desarrolló en dicha época una labor consistente en distinguir entre los estatutos relativos a la conducción del proceso — statuta ad ordinandam litem — y los atinentes a la resolución del fondo del asunto — statuta ad decidendam litem — ${ }^{2}$

Lo anterior vino a crear los cimientos para una separación entre el tribunal y el derecho aplicable a los litigios; ello conduciría a una transformación de la técnica en la que hasta entonces se habían fundamentado, al menos teóricamente, la mayoría de las soluciones adoptadas en los derechos de la antigüedad. La doctrina mayoritaria ha entendido que, hasta entonces, existía siempre una rígida relación entre el tribunal y la ley que había impedido plantearse, en términos generales, el aplicar una ley extranjera en el foro. ${ }^{3}$ Es, pues, en ese mismo escenario en donde comienzan a moldearse las bases del llamado derecho internacional privado, el cual tomó de aquellos primeros trabajos el impulso necesario para su comprensión y manejo por parte de las siguientes generaciones hasta ser el instrumento por excelencia del mundo moderno impregnado por la globalización en todos sus aspectos, en especial, y a los que a nosotros atañe, el jurídico.

En cuanto al primer escrito contentivo de normas sobre la materia, la doctrina señala que es en las Siete Partidas de Alfonso X "El Sabio" en donde se recogen las primeras normas legales del derecho internacional privado de todo el mundo, y fueron escritas en Murcia por Jacobo de las Leyes. Estas normas indican, por ejemplo, que la ley aplicable al régimen económico del matrimonio es la ley del domicilio del marido, que la ley que rige los contratos es la ley del país donde han sido celebrados — lex loci celebrationis - y que la ley que regula los derechos reales es la ley del país donde los

2 Mesa-Moles Martel, María Paz, Génesis y formación del derecho internacional privado, tesis doctoral, septiembre-noviembre de 2016, p. 22, disponible en: https://eciencia.urjc.es/bitstre am / handle / 10115/1058/TESIS\%20MESA\%20MOLES.pdf;jsessionid=16C7F8EOCC4OEDD 1796 8ACOD98DAB23F? sequence $=1$.

3 Idem. 
Esta revista forma parte del acervo de la Biblioteca Jurídica Virtual del Instituto de Investigaciones Jurídicas de la UNAM

bienes están situados — lex rei sitae — ${ }^{4}$ Por ello, teniendo como sustento esta brevísima aproximación al origen de la ciencia del derecho internacional privado, estimamos que es convenientes abordar tanto su aplicación en el contexto del derecho chino, así como del latinoamericano; ello con el fin de poder confrontar las estructuras del uno con los otros y, de esta forma, lograr el propósito del presente escrito.

\section{CHINA Y LA EVOLUCIÓN DE SU DERECHO}

Para China era muy importante, debido a la posición que venía y viene adquiriendo en el escenario mundial, no sólo modernizar sino adaptar sus leyes a las nuevas realidades, ya que, al haber permanecido durante varios siglos en una situación de autarquía, quizás no percibió la necesidad de relacionarse de forma amplia con el mundo exterior; todo ello porque, al leal saber de sus dirigentes, no necesitaba de ello. Sin embargo, una vez que las cosas cambiaron y China empezó a abrirse al mundo, vio que era necesario comprender como funcionaba éste, en especial aquel llamado Occidental, el cual poseía una cultura diametralmente opuesta a la suya y códigos de comportamiento y cosmologías que le eran totalmente novedosos y ajenos, por lo que si quería conquistar aquellos nuevos territorios, (como de hecho lo ha venido haciendo) debía aprender ese reciente lenguaje que era necesario no sólo para comunicarse con ellos, sino para entender su manera de actuar, sus tradiciones y la forma como comenzarían a interrelacionarse.

Lo anterior no significa que en China el derecho haya estado siempre infravalorado o en un nivel muy bajo en cuanto a su desarrollo, ya que es obvio que para mantener un imperio durante tantos siglos se necesita algo más que un muy buen catálogo de normas que puedan mantener siempre coaccionada dicha población, de lo contrario, la vida del pueblo chino hubiera sido un caos, lo que no se ha mostrado nunca durante los diferentes periodos de su historia, de los cuales se tiene conocimiento.

4 Carrascosa González, Javier, "Las primeras normas de conflicto escritas de la Historia. Bolonia, Murcia y Jacobo de las Leyes”, septiembre-noviembre de 2016, disponible en: http: / / accursio.com $/ \mathrm{blog} /$ ? $\mathrm{p}=120$. 
Esta revista forma parte del acervo de la Biblioteca Jurídica Virtual del Instituto de Investigaciones Jurídicas de la UNAM

En el campo jurídico vemos que el derecho chino contiene normas muy antiguas que han sido influenciadas por códigos de conducta o por patrones filosóficos dictados por escuelas tales como el confucianismo (Confucio 551 479 a.C.), las cuales han definido estándares de obediencia y de comportamiento social. ${ }^{5}$ En efecto, Confucio tomaba como el ideal de las personas a aquellas que eran equilibradas, sin miedo, no violentas, con carácter, no vulgares y competentes, ya que si se descuidaban estos comportamientos o se hacían de forma incorrecta, ello conduciría a una anarquía moral o a un trastorno comportamental evidente. ${ }^{6}$

Otra escuela del pensamiento que influenciaría el sistema legal chino sería el daoismo o taoismo (Lao Zi [siglo V a.C.] y Zhuang Zi [siglo IV a.C.]), esto lo haría principalmente desde un punto de vista más filosófico; el mismo señalaba que una persona debería seguir el Tao de una forma que éste no interfiriera en sus deseos, igualmente pregonaba una pasividad política, la no intervención del gobierno en la vida de los habitantes y que éstos pudieran vivir de manera pasiva, sin condicionamientos, en humildad y de acuerdo a las leyes naturales. $^{7}$

Complementando las anteriores tenemos otra escuela del pensamiento que también influenció a dicho sistema, la denominada escuela legalista o fajia, la cual estuvo bajo los dictámenes de Shang Yang (año 338 a.C.); la misma tenía como fundamento el esquema del premio y el castigo e, igualmente, establecía que un mandatario no podía gobernar sin un catálogo de leyes, las cuales deberían ser inicialmente observadas en el seno de las familias o del clan. ${ }^{8}$

El derecho internacional ${ }^{9}$ como tal vino a ser abordado realmente a partir de la derrota de China en la llamada Guerra del Opio o en las guerras

5 The traditional Chinese view of law is primarily influenced by Confucian teachings that an individual should be guided by li (virtue or propriety) rather than by fa (the law). 1 Confucianism is an ethical system that seeks to teach the proper way for all people to behave in society. Zimmerman, James M., A legal Guide to foreing Invested Enterprises, Beijing, American Bar Association-China Law Deskbook, 2010, p. 36.

6 Ibidem, p. 36.

7 Ibidem, p. 39.

8 Ibidem, p. 40.

9 En una anotación que hace Laura Soto von Armin se enuncia el Código Tang del año 624 d.C., el cual se tiene como el primer código de la historia de China, así como la fuente más antigua de derecho internacional privado, es preciso anotar que tal distinción viene a 
Esta revista forma parte del acervo de la Biblioteca Jurídica Virtual del Instituto de Investigaciones Jurídicas de la UNAM

anglo-chinas, las cuales tuvieron lugar entre 1839 y 1842 , y 1856 y 1860 , y fueron causadas por la introducción del opio en ese país a través de la empresa East India Company que lo trasladaba desde la India e hizo de esta sustancia un gran negocio; en este caso, tanto los ingleses como los franceses, rusos y norteamericanos actuaron con mucha astucia y violencia para incrementar sus beneficios en dicho comercio, incluso a costa de las vidas de los chinos, ${ }^{10}$ lo que llevó a las mencionadas guerras por la prohibición que se estableció del comercio de tal producto en ese territorio.

Una vez concluidas las guerras, China se vio en la obligación de suscribir numerosos tratados con los países vencedores,${ }^{11}$ así como la concesión de algunos de sus territorios a estas naciones; especialmente Hong Kong al Reino Unido (Tratado de Chuenpi y Nanking).

Por otro lado, puede anotarse que una verdadera codificación del derecho privado se presentó en 1918 cuando "el Gobierno de Baiyang publica el primer Reglamento sobre ley aplicable, inspirado en el derecho internacional privado alemán y japonés. En dicho Reglamento, se regulaba la ley

presentarse básicamente a partir del surgimiento de los Estados Nación (Tratado de Paz de Westfalia de 1648); ahora el conflicto entre normas pertenecientes a grupos étnicos diversos ya se referenciaban en el conocido Código de Hammurabi del año aproximado de 1780 a.C. (Código de Hammurabi, introducción de Azpiri, Jorge O., Buenos Aires, 2010, p. 98) por lo que estimamos que sea un poco impreciso referenciar al término internacional privado como tal. Soto von Armin, Laura, "La historia del derecho internacional privado en China y sus fuentes”, Anuario Colombiano de Derecho Internacional, Bogotá, vol. 6, 2013. p, 139. En ese sentido, véase Deng, Pan, "El panorama legislativo del derecho internacional privado chino tras la publicación de la nueva ley para la determinación de la ley aplicable a las relaciones con los extranjeros en materia civil”, Revista Jurídica Universidad Autónoma de Madrid, Madrid, núm. 29, 2014-I, p. 53. Zhang, Mo, "Codified Choice of Law in China: Rules, Processes and Theoretic Underpinnings", Journal of International Law and Commercial Regulation, Carolina del Norte, vol. 37, núm. 1, 2011, p. 86.

10 Beeching, Jack, La guerra del opio, trad. de Álvaro Castillo, Barcelona, Plaza \& Janés, S.A. Editores, 1976, p. 465.

11 The unequal treaties — as they are referred to by the Chinese - established a system of extraterritorial privileges under which foreign subjects were exempt from local jurisdiction, and, instead, were subject to their own national authorities for conduct while physically present in China. These extraterritorial privileges included an exemption from jurisdiction of local courts, freedom from arrest by local officials, and the right to a criminal or civil trial by consular or national courts. Prior to the establishment of extraterritorial privileges, China asserted jurisdiction over foreigners and subjected them to local Chinese law. Zimmerman, James M., op. cit., p. 42. 
Esta revista forma parte del acervo de la Biblioteca Jurídica Virtual del Instituto de Investigaciones Jurídicas de la UNAM

aplicable a la capacidad jurídica y de obrar de las personas físicas y jurídicas, al derecho de familia y al derecho de sucesiones". ${ }^{12}$

Años más tarde, se proclamó la República de China y, después de varios períodos de guerras internas, Mao Tsé Tung llegó al poder, instauró el comunismo y llamó a sus territorios República Popular China, volviendo a un período de cierre hacia el exterior y a una restricción del derecho internacional privado ${ }^{13}$ hasta que comenzó su nueva apertura al mundo. Una vez estructurado el Partido Comunista Chino, una de sus primeras acciones fue sustituir al gobierno del Guomingdang y, con ello, todas las referencias a normas influenciadas por Occidente, entre las cuales se encontraban los seis códigos elaborados a partir de modelos europeos, entre ellos la Constitución, el Código de Comercio, el Código Civil, el Código de Procedimiento Civil y el Código Criminal; todas estas normas fueron cambiadas en septiembre de 1949 por el Programa Común de la Conferencia Consultiva del Pueblo Chino, ${ }^{14}$ el cual básicamente suplantó los ideales confucionistas de lealtad hacia la familia y hacia las normas por los de lealtad al Partido y los principios que éste había instituido, influenciados esencialmente por la escuela legalista de Shang Yang.

De 1958 a 1965, China se embarcó en un proyecto mediante el cual buscaba convertirse en una potencia mundial; sin embargo, tal proyecto no contemplaba una reforma o modernización de las leyes, lo que llevó a que la profesión de jurista fuera sometida al destierro, la investigación académica, reducida a su mínima expresión y sus precursores, castigados por el régimen, las facultades de derecho fueron clausuradas y las librerías jurídicas, destruidas por los soldados del Ejército Rojo. En aquel entonces y por muchos años, el derecho internacional privado era visto por los académicos chinos como prohibido, incluso peligroso, por lo que pocos osaban estudiarlo. ${ }^{15}$

La denominada revolución cultural llegó a su fin con la muerte de Mao en 1976; a partir de allí, los nuevos gobernantes chinos decidieron iniciar una apertura de China hacia el exterior, así como hacia la modernización

12 Deng, Pan, op. cit., p. 53.

13 Zhang, Mo, op. cit., p. 86.

14 Zimmerman, James M., op. cit., p. 51.

15 Huo, Zhengxin, "An Imperfect Improvement: The New Conflict of Laws Act of the People's Republic of China”, The International and Comparative Law Quarterly, Cambridge, vol. 60, núm. 4, octubre de 2011, p. 1066. 
Esta revista forma parte del acervo de la Biblioteca Jurídica Virtual del Instituto de Investigaciones Jurídicas de la UNAM

de su industria, ${ }^{16}$ su agricultura, su sistema de defensa, la ciencia y la tecnología al igual que un moderno sistema legal que estuviera acorde con estos cambios. ${ }^{17}$

En 1978 y con la nueva política de apertura, ${ }^{18}$ apareció una normativa denominada Ley de la República Popular China sobre contratos económicos relacionados con intereses extranjeros, la cual posteriormente se complementó con la Ley de Sucesiones, que incluyó en su artículo 36 una norma de conflicto con la cual se buscaba proteger la legítima del heredero chino, tanto en el caso de que los bienes se encontrasen en el extranjero como en el supuesto de que los bienes del causante extranjero se hallasen en China. ${ }^{19}$ A tal fin, este artículo señalaba expresamente una norma de conflicto que desarrollaba conjuntamente el principio de la lex rei sitae y el del domicilio; al respecto establecía lo siguiente: "Los derechos sobre bienes muebles se regirán por la ley de residencia habitual del causante, y los derechos sobre bienes inmuebles, por la ley del lugar donde se hallen”. ${ }^{20}$

De la misma forma se promulga la Ley de Principios Generales del Derecho civil, conocida también como Ley Civil de 1986, la cual incluiría nueve artículos (del 142 al 150) en los que se establecieron normas de conflicto en materia de nacionalidad, residencia, capacidad civil, propiedad, contratos, obligaciones extracontractuales, matrimonio y divorcio, régimen de alimentos y responsabilidad parental y sucesiones. En igual sentido, se incluyeron ciertas disposiciones relativas a los límites de la aplicación del derecho material extranjero en el territorio chino, esto es, normas materiales imperativas que tienden a garantizar su orden público interno. ${ }^{21}$ En ese sentido, se puede apreciar que en 2002, la Asamblea Popular Nacional decidió emprender un proyecto con miras a elaborar un documento normativo que regulara las relaciones entre los chinos y los extranjeros de una forma más

16 Cesarín, Sergio M., "Ejes y estrategias del desarrollo económico chino: enfoques para América Latina y el Caribe”, China y América Latina. Nuevos enfoques sobre cooperación y desarrollo. ¿Una segunda ruta de seda?, Buenos Aires, Red de Centros de Estudios de Asia y el Pacífico de América Latina y El Caribe, 2005, p. 5.

17 Deng, Pan, op. cit., p. 53.

$18 \mathrm{Yu}$, Shuhong et al., "The Closest Connection Doctrine in the Conflict of Laws in China", Chinese Journal of International Law, Oxford University Press, vol. 8, núm. 2, 2009, p. 424.

19 Deng, Pan, op. cit., p. 54

20 Idem.

21 Ibidem, p. 55. 
Esta revista forma parte del acervo de la Biblioteca Jurídica Virtual del Instituto de Investigaciones Jurídicas de la UNAM

homogénea. Tal labor culminaría con la promulgación por parte de dicho órgano legislativo de una reglamentación denominada Ley para la Determinación de la Ley Aplicable a las Relaciones con los Extranjeros en Materia Civil (en adelante, Ley China), el 28 de octubre de 2010. Esta ley entraría en vigor el 1o. de abril de 2011, con lo que se convirtió en la primera ley de derecho internacional privado en la historia de ese país, por lo cual será el fundamento del presente ensayo.

\section{EL DERECHO INTERNACIONAL PRIVADO}

EN LATINOAMÉRICA

\section{El derecho civil en Latinoamérica (principalmente en Brasil) esencialmente} tiene sus orígenes en el derecho español de la época, ${ }^{22}$ en especial en las Siete Partidas de Alfonso X, "El Sabio", el cual continuó hasta la progresiva independencia de cada una de las colonias españolas y la portuguesa, donde cada nuevo Estado fue configurando su propio derecho a partir de sus propias normas, así como de normativas extranjeras, especialmente el Código Napoleón. ${ }^{23}$

22 En tal sentido señala Fernández Rozas que: "Dentro del estricto campo del derecho privado o, si se quiere, en el interior de las raíces mediatas del derecho romano, no puede negarse que la identidad jurídico-cultural del derecho latinoamericano se extiende durante el largo período de dominación colonial. El derecho indiano aplicable a los territorios de ultramar construyó las bases de lo que luego de la independencia política comenzó a adquirir identidad nacional a través de la codificación. De hecho, la independencia de la América española marcó el fin de la poca indiana, pero no del derecho indiano. El derecho indiano que rigió en América española desde la poca de los descubrimientos hasta la codificación, es decir, en términos generales, desde fines del siglo XV hasta la segunda mitad del siglo XIX, estuvo conformado por elementos del derecho castellano, indígena y el específico”. Fernández Rozas, José Carlos, El Código de Napoleón y su influencia en América Latina: Reflexiones a propósito del segundo centenario, Mérida, SABER ULA-Universidad de los Andes, 2006, p. 169.

23 Nuevamente, señala Fernández Rozas que: "a partir del Código peruano de 1852, considerado como el primer Código americano autónomo, la idea de introducir el sistema al Code brilla por su ausencia. Y, en esta línea de alejamiento del modelo napoleónico, el Código Civil chileno constituye el ejemplo más destacado. Ello es así por cuanto en su contenido predomina incontrastablemente la tradición romano-castellana, y dentro de ella de manera principal la proveniente de las Siete Partidas. Se trata de una actitud que no debe sorprender por cuanto ya la idea de codificación que Bello plantea en su propuesta es la de la consolidación del derecho, 
Esta revista forma parte del acervo de la Biblioteca Jurídica Virtual del Instituto de Investigaciones Jurídicas de la UNAM

En cuanto al derecho internacional privado, vemos que la armonización de las reglas de conflicto de leyes no presenta inconvenientes debido a que muchos Estados latinoamericanos derivaron sus sistemas jurídicos de un tronco hispánico común; ${ }^{24}$ a partir de dicha premisa encontramos una de las primeras manifestaciones a favor de la unificación del derecho en el territorio latinoamericano, el denominado Congreso de Panamá o Anfictiónico ${ }^{25}$ de 1826, que se convocaría para el 7 de diciembre de 1824 desde Lima por el libertador Simón Bolívar, quien en ese entonces fungía como presidente de Perú, y cuyo objeto principal era buscar la unión o la confederación de los Estados de América; en uno de los apartados de dicha convocatoria, Bolívar señalaría:

Cuando, después de cien siglos, la posteridad busque el origen de nuestro derecho público, y recuerden los pactos que consolidaron su destino, registrarán con respeto los protocolos del Istmo. En él, encontrarán el plan de las primeras alianzas, que trazará la marcha de nuestras relaciones con el universo. ¿Qué será entonces el Istmo de Corinto comparado con el de Panamá? ${ }^{26}$

Por otro lado, no debe olvidarse que si bien el origen del derecho internacional privado moderno tuvo asiento en el continente europeo, fue en América Latina donde se presentaron los primeros movimientos unificadores de la materia; en efecto, el Congreso de Lima de 1877 constituye la primera gran manifestación en favor de su unificación a nivel regional. El Tratado de Lima sobre derecho internacional privado, si bien por ciertas

esto es, recoger el derecho vigente en el contexto iberoamericano, siendo el derecho español la vertiente más abundante en materia una vez expurgado de muchos de sus defectos con la aportación de los códigos extranjeros. Y es precisamente aquí donde el Código de Napoleón ocupa un lugar importante. Éste es un dato digno de consignar dado que el Código Civil chileno tuvo una extraordinaria difusión, matizada desde luego, por parte de diversos países americanos como tendremos ocasión de comprobar, pasando a tener en este continente un lugar similar al alcanzado en Europa por el Código de Napoleón”. Fernández Rozas, José Carlos, op. cit., p. 173.

24 Helguera, Enrique, El derecho internacional privado mexicano y el Código de Bustamante, México, UNAM, Instituto de Derecho Comparado, 1962, p. 29.

25 Fundación Biblioteca Ayacucho, septiembre-noviembre de 2016, disponible en: http: / / www.bibliotecayacucho.gob.ve/fba/index.php?id=21\&tx_ttnews\% 5 Btt_news $\% 5 D=1532$ \&tx_ttnews $\% 5$ BbackPid\%5D=2\&cHash $=6 a 1 c 818917$.

26 Yanes, Francisco Javier y Mendoza Montilla, Cristóbal, Colección de documentos relativos a la vida pública del Libertador de Colombia y del Perú, Simón Bolívar, para servir a la historia de la independencia de Suramérica, Caracas, t. IV, 1826, p. 175. 
Esta revista forma parte del acervo de la Biblioteca Jurídica Virtual del Instituto de Investigaciones Jurídicas de la UNAM

razones nunca fue ratificado, se estructuraba en 60 artículos divididos en 8 capítulos, y en él se incluían reglas sobre conflicto de leyes en materia de Estado y capacidad de las personas, sucesiones, competencia judicial internacional, entre otras. Posteriormente, en 1879 tendría lugar el Congreso de Montevideo donde se adoptaron los primeros tratados de derecho internacional privado que entraron en vigor en el mundo. ${ }^{27}$

Tal esfuerzo en favor del desarrollo del derecho internacional privado se continuaría a nivel regional con las llamadas Conferencias Panamericanas, realizadas en Washington D.C., en 1889; en México, en 1902; en Rio de Janeiro, en 1906; en Buenos Aires, en 1910; en Santiago de Chile, en 1923, y finalmente en La Habana, en 1928, donde se aprobó el Proyecto de Código de Derecho Internacional Privado, preparado por el profesor cubano Antonio Sánchez de Bustamante y Sirvén y el cual se convertiría en el instrumento normativo más importante sobre la materia que hasta ese momento se había realizado, ya que era el primer Código completo que estaba compuesto por 437 artículos que abarcan reglas generales de derecho civil internacional, derecho mercantil internacional, derecho procesal internacional y derecho penal internacional, incluyendo la extradición; ${ }^{28}$ el mismo está vigente en Bolivia, Brasil, Chile, Costa Rica, Cuba, Ecuador, Guatemala, Haití, Honduras, Nicaragua, Panamá y Venezuela. ${ }^{29}$

Es de anotar que posteriormente se celebraron más Conferencias Panamericanas: en Montevideo, en 1933; en Lima, en 1938, y en Bogotá, en 1948, que sería la última que se celebraría con relación al formato que se venía llevando a cabo; a partir de allí se establece un Comité de Jurisconsultos, es decir, un cuerpo consultivo en asuntos jurídicos internacionales, el cual se encargaría de la promoción del derecho internacional privado en toda la región. Después de varios años de labor, se establece un nuevo modelo de unificación de las normas materiales de derecho internacional privado, el cual sería el

27 Garro, Alejandro M., “Armonización y unificación del derecho privado en América Latina: esfuerzos, tendencias y realidades”, Revista de la Facultad de Ciencias Jurídicas y Políticas, Caracas, Universidad Central de Venezuela, núm. 85, 1992, p. 287.

28 Siqueiros, José Luis, "La codificación del derecho internacional privado en el continente americano”, Revista Jurídica, México, núm. 14, 1982, p. 239.

29 De igual manera ha de tenerse presente que en la actualidad hay muchos países latinoamericanos que tienen sus propias leyes de derecho internacional privado como lo son: Venezuela, República Dominicana y Panamá, y en otros existen proyectos de codificación como en Uruguay, Paraguay, México etcétera. 
que conocemos como las Conferencias Especializadas de la Organización de los Estados Americanos (OEA) en Derecho Internacional Privado; entre las que se encuentran: Panamá 1975 (CIDIP I), ${ }^{30}$ Montevideo 1979 (CIDIP II), ${ }^{31}$ La Paz 1984 (CIDIP III), ${ }^{32}$ Montevideo 1989 (CIDIP IV), ${ }^{33}$ México D.F. 1994 (CIDIPV),${ }^{34}$ Washington D.C. 2002 (CIDIP VI).$^{35}$

\section{EL DERECHO INTERNACIONAL PRIVADO EN CHINA}

\section{Como quedó señalado, China es un Estado unitario, puesto que el gobierno central tiene una amplia potestad sobre todas la regiones que están bajo su}

30 Convención Interamericana sobre conflictos de leyes en materia de letras de cambio, pagarés y facturas. Convención Interamericana sobre conflictos de leyes en materia de cheques. Convención Interamericana sobre arbitraje comercial internacional. Convención Interamericana sobre exhortos o Cartas Rogatorias. Convención Interamericana sobre recepción de pruebas en el extranjero. Convención Interamericana sobre régimen legal de poderes para ser utilizados en el extranjero.

31 Convención Interamericana sobre eficacia extraterritorial de las sentencias y laudos arbitrales. Convención Interamericana sobre cumplimiento de medidas cautelares. Convención Interamericana sobre prueba e información del derecho. Protocolo Adicional a la Convención Interamericana sobre exhortos o cartas rogatorias. Convención Interamericana sobre conflictos de leyes en materia de cheques. Convención Interamericana sobre conflictos de leyes en materia de sociedades mercantiles. Convención Interamericana sobre domicilio de las personas físicas en el derecho internacional privado. Convención Interamericana sobre normas generales de derecho internacional privado.

32 Convención Interamericana sobre conflictos de leyes en materia de adopción de menores. Convención Interamericana sobre personalidad y capacidad de personas jurídicas en el derecho internacional privado. Convención Interamericana sobre competencia en la esfera internacional para la eficacia extraterritorial de las sentencias extranjeras. Protocolo Adicional a la Convención Interamericana sobre recepción de pruebas en el extranjero.

33 Convención Interamericana sobre restitución internacional de menores. Convención Interamericana sobre obligaciones alimentarias. Convención Interamericana sobre contratación de transporte internacional de mercaderías por carretera.

34 Convención Interamericana sobre derecho aplicable a contratos internacionales. Convención Interamericana sobre tráfico internacional de menores.

35 La Ley Modelo Interamericana sobre Garantías Mobiliarias. Carta de Porte Directa Uniforme Negociable Interamericana para el transporte internacional de mercaderías por carretera. Carta de Porte Directa Uniforme No-Negociable Interamericana para el transporte internacional de mercaderías por carretera. 
Esta revista forma parte del acervo de la Biblioteca Jurídica Virtual del Instituto de Investigaciones Jurídicas de la UNAM

régimen administrativo, especialmente, lo que se conoce como tierra firme; esto porque hay zonas que tienen este tipo de régimen especial como Hong Kong, Macao y Taiwan, ${ }^{36}$ que configuran dos sistemas jurídicos en lo que se conoce como la política de un solo país.

Lo anterior conlleva a que las normas del derecho internacional privado chino tengan una aplicación restringida en dichos territorios, toda vez que éstas regularán las relaciones jurídicas en la China continental, ya que debido al estatus especial que tienen como regiones administrativas especiales, dichas normas no aplican allí, por lo que estarían cada una de ellas diferenciadas en cuanto a su aplicabilidad en cada uno de aquellos territorios. ${ }^{37}$ China actualmente cuenta con la denominada Ley para la Determinación de la Ley Aplicable a las Relaciones con los Extranjeros en Materia Civil, del 28 de octubre de 2010 y que entró en vigor el 1o. de abril de 2011.

\section{VI. ÁMBITO DE APLICACIÓN MATERIAL DE LA NUEVA LEY CHINA}

En cuanto a su estructura, la Ley China, como su nombre lo indica, aborda únicamente las cuestiones relacionadas con la determinación de la ley aplicable a situaciones con elementos foráneos y se compone de 52 artículos repartidos en 8 títulos o capítulos ${ }^{38}$ que señalan la materia a la cual ha de aplicarse la ley respecto de relaciones jurídicas de tipo civil que tienen los nacionales chinos con los extranjeros y los eventuales litigios que surjan de las mismas. ${ }^{39}$

36 Véanse Soto von Armin, Laura, op. cit., p. 134; Zhang, Mo, op. cit., p. 85; Deng, Pan, op. cit., p. 53.

37 Huang, Jie, "Interregional Recognition and Enforcement of Civil and Commercial Judgements: Lessons for China and US and EU Laws”, Journal of Private International Law, vol. 6, núm. 1, 2010, p. 112, septiembre-noviembre de 2016, disponible en: http: / /works.bepress.com/ jie_huang/4.

38 Capítulo primero: Disposiciones generales. Capítulo segundo: Sujetos civiles. Capítulo tercero: Matrimonio y familia. Capítulo cuarto: Sucesiones. Capítulo quinto: Derechos reales. Capítulo rexto: Obligaciones. Capítulo séptimo: Derechos de propiedad intelectual. Capítulo octavo: Disposiciones suplementarias

39 Artículo 1o. 
Esta revista forma parte del acervo de la Biblioteca Jurídica Virtual del Instituto de Investigaciones Jurídicas de la UNAM

En primer lugar podemos apreciar, respecto a los destinatarios, que esta normativa, a diferencia de algunas latinoamericanas que aquí abordaremos, señala taxativamente la calidad que ha de tener en principio una de las partes para que sea aplicable, esto es, ser nacional chino; ello lo hace en su artículo 1o. que indica que "para las relaciones entre los ciudadanos chinos con ciudadanos de terceros Estados"; en este caso, haciendo una aproximación comparativista, podemos apreciar que el Código de Bustamante, como norma armonizadora, remite a un evento particular, pues señala igualmente en su artículo 1o. que "los extranjeros que pertenezcan a cualquiera de los Estados contratantes gozan"; imaginamos que en tal caso se quiso hablar de los nacionales o habitantes, ya que no sabemos hasta qué punto se puede ser extranjero en su propio país; sin embargo creemos que el espíritu de ambas normas es el de regular las relacionas jurídicas entre un nacional y un extranjero y los derechos y obligaciones que de ellas emanan. ${ }^{40}$

Otra de las novedades de dicha ley es la admisión de la aplicación de una ley extranjera a situaciones jurídicas que deban ser conocidas por los tribunales chinos ${ }^{41}$ esto es revolucionario, ya que, hasta hace muy poco, aplicar por parte de tales tribunales una ley foránea a un litigio interno era tenido como una "misión imposible", debido a que en el país existía un sentimiento muy arraigado en cuanto al rechazo de las leyes extranjeras o aquellas con tintes occidentales. ${ }^{42}$ En América Latina, tal principio lo encontramos en

40 En ese aspecto la Ley de Derecho Internacional Privado de Venezuela no señala nada con relación a la calidad de las partes en cuanto a su nacionalidad. El artículo 1o. del Código de Derecho Internacional Privado de Panamá (Ley 7a. de 2014) se acerca un poco a la versión de la Ley China al indicar que: “determinará la ley aplicable a las relaciones jurídicas que comporten tráfico jurídico internacional. También regirá lo atinente a la nacionalidad panameña, que le permita al juez tomar en cuenta la determinación del derecho aplicable dentro de una relación de derecho internacional”. De igual manera el artículo 1o. de la Ley núm. 544-14 de Derecho Internacional Privado de la República Dominicana del 15 de Octubre de 2014 indica sin hacer referencia a nacionalidad alguna que "esta ley tiene por objeto regular las relaciones privadas internacionales de carácter civil y comercial en la República Dominicana”. El proyecto de Ley General de Derecho Internacional Privado del Uruguay (11 de septiembre de 2013); y el Proyecto Argentino, al igual que la Ley Venezolana, no señalan nada al respecto.

${ }_{41}$ El artículo 2o. de la Ley China señala que: "No obstante, si existen disposiciones especiales por razón de la materia contenidas en las leyes de terceros Estados vinculadas con la cuestión, éstas podrán prevalecer sobre las disposiciones de la presente ley”.

42 Zhang, Mo, op. cit., p. 90. 
Esta revista forma parte del acervo de la Biblioteca Jurídica Virtual del Instituto de Investigaciones Jurídicas de la UNAM

el artículo 408 del Código de Bustamante, ${ }^{43}$ en el artículo 2o. de la Convención Interamericana sobre normas generales del derecho internacional privado (Montevideo, 1979) ${ }^{44}$ en el artículo 20. ${ }^{45}$ de la Ley Venezolana de Derecho Internacional Privado (en adelante, Ley Venezolana), en el artículo 4o. de la Ley núm. 544-14 de Derecho Internacional Privado de la República Dominicana $^{46}$ (en adelante, Ley Dominicana), en el artículo 167 del Código de Derecho Internacional Privado de Panamá (en adelante, Ley Panameña) y en los artículos 2595 y 2596 del Nuevo Código Civil y Comercial de la Nación Argentina (en adelante, Ley Argentina).

De igual forma, podemos apreciar que entre las características que nos brinda la Nueva Ley China se encuentra el desarrollo del principio de la lex specialis generalibus derogant y la inclusión del concepto de "los vínculos más estrechos" ${ }^{\$ 7}$ para poder definir finalmente la ley aplicable a un determinado litigio; ${ }^{48}$ lo cual podrá obrar de manera subsidiaria tal y como lo señalan los incisos 2) y 3) del artículo 2o.: "A falta de previsión especial de la ley a la que puede remitirse la presente ley, se aplicará entonces la ley que tenga los vínculos más estrechos”. Este concepto en el derecho internacional privado latinoamericano, al igual que como sucede en el ámbito jurídico europeo,

43 "Los jueces y tribunales de cada Estado contratante aplicarán de oficio, cuando proceda, las leyes de los demás sin perjuicio de los medios probatorios a que este capítulo se refiere”.

44 "Los jueces y autoridades de los Estados Partes estarán obligados a aplicar el derecho extranjero tal como lo harían los jueces del Estado cuyo derecho resultare aplicable, sin perjuicio de que las partes puedan alegar y probar la existencia y contenido de la ley extranjera invocada”.

45 "El derecho extranjero que resulte competente se aplicará de acuerdo con los principios que rijan en el país extranjero respectivo, y de manera que se realicen los objetivos perseguidos por las normas venezolanas de conflicto".

46 "Leyes especiales. Las disposiciones de esta ley se aplicarán bajo reserva de lo dispuesto en leyes especiales reguladoras de relaciones privadas internacionales. Párrafo. En caso de contradicción, prevalecerán las leyes reguladoras de relaciones privadas internacionales".

47 Este concepto desarrollado por el jurista británico Jhon Westlake en su tratado de derecho internacional privado de 1859, retomado en los numerales 1o. y 2o. del artículo 4o. del Convenio de Roma de 1980 (80/934/CEE) sobre la ley aplicable a las obligaciones contractuales y que señalan que: "En la medida en que la ley aplicable al contrato no hubiera sido elegida conforme a las disposiciones del artículo 3o., el contrato se regirá por la ley del país con el que presente los vínculos más estrechos".

48 Nord, Nicolás y Vieira da Costa Cerqueira, Gustavo, "Comments on the Chinese new Statute on Conflict of Laws: A European Perspective", Chinese Yearbook of Private International Law and Comparative Law, vol. 14, p. 78. 
Esta revista forma parte del acervo de la Biblioteca Jurídica Virtual del Instituto de Investigaciones Jurídicas de la UNAM

ha sido recogido en la Convención Interamericana (México, 1994) sobre la ley aplicable a las obligaciones contractuales en su artículo 90. ${ }^{49}$ Hay que tener presente que en este caso, el campo de aplicación de la nueva Ley China es más amplio, ya que no se circunscribe únicamente al campo contractual, sino a todo el civil, donde una situación jurídica amerite definir una ley en particular.

La nueva Ley China, al desprenderse de ese sistema un poco ortodoxo como lo es el confucionista debido a la libertad que tienen las partes de regular sus propias relaciones, se acerca de manera significativa al sistema occidental y adopta el modelo generado en un principio por el Convenio de Roma de 1980 (80/934/CEE) sobre la ley aplicable a las obligaciones contractuales, así como la Convención Interamericana (México 1994) sobre la materia que desarrolla el principio de la autonomía de las partes, ${ }^{50}$ donde se les permite una elección de aquella normativa que estimen más conveniente y que sea aplicable a su futura relación contractual u obligacional.

Tal principio se ha estado imponiendo en el ámbito mundial, no sólo desde el punto de vista convencional, sino también estatal; éste se desarrolla de manera expresa en algunas legislaciones latinoamericanas como lo indica, entre otros, el artículo $29^{51}$ de la Ley Venezolana. En este caso es importante anotar que la autonomía de la voluntad de las partes, que por primera vez se desarrolla a nivel legal en China, ${ }^{52}$ no únicamente se circunscribe al campo de las obligaciones contractuales, sino también a todas las relaciones civiles. ${ }^{53}$

49 De forma análoga el párrafo del artículo 60 de la Ley núm 544-14 de derecho internacional privado de la República Dominicana del 15 de octubre de 2014.

50 Artículo 3o.

51 "Las obligaciones convencionales se rigen por el derecho indicado por las partes". De igual manera el artículo 58 de la Ley Dominicana, "El contrato se rige por la ley elegida por las partes”, el artículo 75 de la Ley Panameña, el artículo 2596 inciso segundo del Código Argentino "Cuando, en una relación jurídica, las partes eligen el derecho de un determinado país, se entiende elegido el derecho interno de ese Estado, excepto referencia expresa en contrario", así como el artículo 2651.

52 Zhang, Mo, op. cit., p. 100

53 "Regirá el principio de libertad de elección de ley aplicable mediante la autonomía de las partes en las materias contenidas en la presente ley". 
Esta revista forma parte del acervo de la Biblioteca Jurídica Virtual del Instituto de Investigaciones Jurídicas de la UNAM

\section{Orden público}

Una ley extranjera que ha sido designada como aplicable a un determinado litigio, de acuerdo a las reglas de conflicto del derecho local, puede ser excepcionalmente excluida si la misma va en contra de principios básicos y de valores intrínsecos que distinguen a una comunidad de las otras. Cuando esto se presenta, se activa un dispositivo conocido como la protección del orden público; esto es, aquella reacción de defensa mediante la cual se protege el orden jurídico interno del país y sus intereses vitales, al evitar elementos perturbadores extraños y al impedir un debilitamiento profundo del orden establecido. ${ }^{54}$

En China, al igual que en la mayoría de los países, esto no ha sido la excepción; máxime porque es un territorio que se ha visto influenciado desde hace siglos por preceptos adscritos al confucianismo, el cual ha estado muy apegado a las tradiciones del pueblo chino; razón ésta por la cual las reglas de orden público vuelven a encontrar un lugar en la nueva regulación internacional china; es así como la normativa vigente no sólo incluye esta clase de patrones en cuanto a la aplicación de leyes extranjeras, sino como limitante al principio de libertad contractual de las partes. En efecto, los artículos 4o. ${ }^{55}$ y $50 .{ }^{56}$ de dicha ley señalan expresamente la imperatividad que tienen tales preceptos frente a cualquier otra norma o sentencia extranjera que pretenda desconocer los valores y costumbres vigentes en el territorio y para el pueblo chino. ${ }^{57}$

En el campo normativo internacional, así como en el latinoamericano, la cuestión del orden público también es objeto de regulación, no sólo por los derechos nacionales de cada Estado, sino por el derecho convencional. En

54 Nova Monreal, Eduardo, Defensa de las nacionalizaciones ante tribunales extranjeros, México, UNAM, Instituto de Investigaciones Jurídicas, 1976, p. 124.

55 "Si existieran disposiciones imperativas sobre relaciones civiles con elementos de extranjería en la República Popular de China, dichas disposiciones serán directamente aplicables".

56 "Si la aplicación de leyes extranjeras pudiera dañar el interés público y social de la República Popular de China, las leyes de ésta última serán aplicables”.

57 Huo, Zhengxin, "Highlights of China's New Private International Law Act: From the Perspective of Comparative Law”, septiembre-noviembre de 2016, p. 653, disponible en: https: / /ssl.editionsthemis.com/uploaded/revue/article/5973_45-3\%20Huo.pdf. 
Esta revista forma parte del acervo de la Biblioteca Jurídica Virtual del Instituto de Investigaciones Jurídicas de la UNAM http://www.juridicas.unam.mx/ https://biblio.juridicas.unam.mx/bjv https://revistas.juridicas.unam.mx/ DOI: http://dx.doi.org/10.22201/iij.24487872e.2018.18.12109

materia contractual internacional, en primer lugar, hemos de dirigirnos al inciso 3) del Artículo 3o. Convenio de Roma de 1980 (80/934/CEE) sobre la ley aplicable a las obligaciones contractuales el cual indica que:

La elección por las partes de una ley extranjera, acompañada o no de la de un tribunal extranjero, no podrá afectar, cuando todos los demás elementos de la situación estén localizados en el momento de esta elección en un solo país, a las disposiciones que la ley de ese país no permita derogar por contrato, denominadas en lo sucesivo "disposiciones imperativas".

De igual manera, el tema se aborda en el artículo 7o. de la Convención Interamericana sobre normas de derecho internacional privado de 1979 (en adelante, Convención de Montevideo de 1979) en el Código de Bustamante, el cual dedica alrededor de 23 artículos $^{58}$ a la regulación del orden público en cuestiones de derecho de familia, civil, así como del contractual internacional. Las Leyes Dominicana, ${ }^{59}$ Panameña, ${ }^{60}$ Venezolana ${ }^{61}$ y Argentina ${ }^{62}$ de derecho internacional privado abordan la cuestión en términos muy similares a Ley China, por lo que se estima que las regulaciones relativas a la protección del orden público aquí estudiadas guardan una relación

58 Artículos 51, 59, 68, 78, 76, 90, 91, 120, 129, 134, 145, 148, 160, 175, 178, 179, 188, 189, 192, 197, 212, 246 y 283.

59 Artículo 7o. inciso 2) Orden Público Dominicano: Comprende las disposiciones o principios imperativos no derogables por la voluntad de las partes; 3) Orden Público Internacional: Es el conjunto de principios que inspiran el ordenamiento jurídico dominicano y que reflejan los valores de la sociedad en el momento de ser apreciado. Artículo 86: No se aplica la ley extranjera sí sus efectos son incompatibles con el orden público internacional.

60 Artículo 7o. Los efectos jurídicos de un acto o ley extranjera o internacional no serán reconocidos, total o parcialmente, cuando su aplicación vulnere o viole: 1 . Principios fundamentales. 2. Derechos esenciales. Instituciones básicas del ordenamiento jurídico panameño. La no aplicación del derecho o la ley extranjera será suplida por el derecho interno.

${ }^{61}$ Artículo 5o. Las situaciones jurídicas creadas de conformidad con un derecho extranjero que se atribuya competencia de acuerdo con criterios internacionalmente admisibles producirán efectos en la República, a no ser que contradigan los objetivos de las normas venezolanas de conflicto, que el derecho venezolano reclame competencia exclusiva en la materia respectiva, o que sean manifiestamente incompatibles con los principios esenciales del orden público venezolano.

62 Código Civil. Artículo 2600.- Orden público. Las disposiciones de derecho extranjero aplicables deben ser excluidas cuando conducen a soluciones incompatibles con los principios fundamentales de orden público que inspiran el ordenamiento jurídico argentino. 
Esta revista forma parte del acervo de la Biblioteca Jurídica Virtual del Instituto de Investigaciones Jurídicas de la UNAM

muy estrecha en cuanto a la protección de costumbres y valores inherentes a cada territorio donde las mismas son aplicables y tienen los mismos efectos en cuanto a una contradicción que frente a ellas se presente con una ley o decisión judicial extranjera, la cual deberá ser descartada en favor de la normativa nacional.

\section{Aplicación de la ley extranjera}

Existe en la Ley China una cuestión algo particular con relación a otras normativas que regulan cuestiones de derecho internacional privado, y es que hay cierta inclinación a dar aplicación a aquella ley del lugar que presenta los vínculos más estrechos con la situación que da origen a la cuestión litigiosa. Al igual que el artículo 2o., el artículo 6o. de la misma ley indica que: "Cuando el derecho extranjero sea aplicable a una relación con elementos de extranjería y existan diferentes sistemas legales implementados en diversas regiones del país extranjero, la ley de la región que presente los vínculos más estrechos con la relación civil con elementos de extranjería será la aplicable”.

Entendemos que con lo anterior se busca que exista una mayor certeza en cuanto a la normativa aplicable, y la novedad de esta cuestión radica en el hecho de que tal señalamiento tiene aplicación, esencialmente, frente a aquellos sistemas políticos que se componen de varios Estados federados, los que cada uno de ellos puede tener su propio derecho estatal diferente del federal, el cual puede estar más conectado con una situación jurídica que los otros. Esta particularidad no es muy común en los sistemas normativos latinoamericanos de derecho internacional privado, en especial al hacer dicha distinción; simplemente donde se halle la misma, ésta definirá la ley del lugar que guarde la conexión más estrecha y significativa con la situación jurídica. En ese sentido, creemos que la normativa latinoamericana que más se acerca a tal principio es el inciso b) del artículo 2595 del Nuevo Código Civil Argentino ${ }^{63}$ que indica:

si existen varios sistemas jurídicos covigentes con competencia territorial o personal, o se suceden diferentes ordenamientos legales, el derecho aplicable se deter-

63 En tal sentido el artículo 87 de la Ley Dominicana. 
Esta revista forma parte del acervo de la Biblioteca Jurídica Virtual del Instituto de Investigaciones Jurídicas de la UNAM

mina por las reglas en vigor dentro del Estado al que ese derecho pertenece y, en defecto de tales reglas, por el sistema jurídico en disputa que presente los vínculos más estrechos con la relación jurídica de que se trate.

Otra de las novedades que aparece en la parte general de la Ley China es la que se relaciona con el tema de la prescripción, ${ }^{64}$ esencialmente en materia civil, la cual de acuerdo a ésta, se regulará por la norma que resulte aplicable al litigio internacional; sea el derecho chino o uno extranjero; ahora el que aparezca como apto será el que defina los plazos en los cuales se aplicará tal medida. En otras palabras, el plazo señalado para la prescripción y los efectos que de la aplicación de la misma deriven deberán ser acordes con las leyes de orden público, ya que si la ley local ofrece un plazo más amplio al de la ley extranjera, esa diferencia podría ser tenida como una vulneración de derechos que son protegidos por normas imperativas. En este caso hablamos de "novedad", ya que en el campo del derecho latinoamericano la cuestión básicamente es del resorte de los derechos nacionales y pocas veces se trata a nivel de normas de conflicto de leyes.

En el campo del derecho uniforme, la cuestión de la prescripción ha sido abordada por la Convención sobre la prescripción en materia de compraventa internacional de mercaderías de 1974, la cual señala taxativamente en su artículo 8o. que el plazo de prescripción para las cuestiones que regula dicho instrumento será de cuatro años. Entendemos, pues, que la referencia a tal normativa tendrá aplicación tanto en el ordenamiento jurídico chino como en el de los Estados latinoamericanos, siempre y cuando hayan suscrito tal Convenio o que, en su defecto, el mismo resulte aplicable frente a la remisión que hagan a él las normas de derecho internacional privado del país requerido. En cuanto a los aspectos civiles de las relaciones internacionales, en América Latina tiene aplicación el Tratado de Montevideo de 1989, el cual aborda lo relativo a la prescripción en sus artículos $51^{65} \mathrm{y}$

64 Artículo 7o.

65 Artículo 51. La prescripción extintiva de las acciones personales se rige por la ley a que las obligaciones correlativas están sujetas. Artículo 52. La prescripción extintiva de acciones reales se rige por la ley del lugar de la situación del bien gravado. Artículo 53. Si el bien gravado fuese mueble y hubiese cambiado de situación, la prescripción se rige por la ley del lugar en que se haya completado el tiempo necesario para prescribir. Artículo 54. La prescripción adquisitiva de bienes muebles o inmuebles se rige por la ley del lugar en que están situados. Artículo 55. Si el bien fuese mueble y hubiese cambiado de situación, la prescripción se rige por la ley del lugar en que se haya completado el tiempo necesario para prescribir. En Argen- 
Esta revista forma parte del acervo de la Biblioteca Jurídica Virtual del Instituto de Investigaciones Jurídicas de la UNAM

siguientes, generando más claridad respecto al tipo de situación a la que se aplica, y el artículo 295 del Código de Bustamante. ${ }^{66}$

En cuanto a la determinación de la ley aplicable, hay que tener presente que, en materia de calificaciones frente a situaciones con elementos extranjeros o creadas en el exterior, la Ley China se inclina por llevarla a cabo a partir de su derecho local, esto es la lege fori, en lugar de someterla a la ley del lugar donde nació la situación que se califica, es decir, la lege causae. Lo anterior queda bastante claro al tenor del artículo 8o. que señala: "La ley del foro deberá aplicarse a la calificación de la naturaleza de las relaciones civiles con elementos de extranjería"; ello implica la aplicación del principio de territorialidad del derecho chino en cuanto a la calificación de situaciones jurídicas de la que se trata, ${ }^{67}$ en especial cuando el juez tiene frente a él un caso con elementos extranjeros que ha de resolver.

Ahora, el problema se puede suscitar en el momento en que se deba calificar una situación creada en el extranjero que no tenga un antecedente similar o sea desconocida en China, lo que puede traer ciertos problemas al instante de valorar los elementos que han de conducir a la sentencia. En el derecho latinoamericano tal posición no es tan estricta, toda vez que el juez puede valorar la institución tanto desde el punto de vista de la lege causae como de la lex fori; lo importante es que tenga certeza de lo que va a juzgar. Con relación a ello podemos ver que la Convención de Montevideo de 1979, en materia de calificaciones, se acerca a la posición de la Ley China, en relación a que sólo cuando medie una excepción podrá ser de aplicación la lex fori, en cuanto a la calificación de la institución que analiza el tribunal. En efecto, la misma en su artículo 30. ${ }^{68}$ determina que: "Cuando la ley de un Estado Parte tenga instituciones o procedimientos esenciales para su adecuada aplicación y no estén contemplados en la legislación de otro Estado Parte, éste podrá negarse a aplicar dicha ley, siempre que no tenga instituciones o procedimientos análogos".

tina se regula por el artículo 2671 del Nuevo Código Civil: "La prescripción se rige por la ley que se aplica al fondo del litigio".

66 "La prescripción de las acciones nacidas de los contratos y actos mercantiles se ajustará a las reglas establecidas en este Código respecto de las acciones civiles”.

67 Zhang, Mo, op.cit., p. 110.

68 Tal prohibición la encontramos igualmente en el artículo 9o. de la Ley Venezolana, en el artículo 2595 del Nuevo Código Civil Argentino, en el artículo 410 del Código de Bustamante, entre otros. 
Esta revista forma parte del acervo de la Biblioteca Jurídica Virtual del Instituto de Investigaciones Jurídicas de la UNAM

Ahora, contrario a lo que señala la Ley China respecto al hecho de que aunque se acepta la aplicación de una ley extranjera a una situación jurídica que está siendo conocida por los tribunales chinos, tal aplicación excluirá las normas de conflicto de dicho país donde aquella se ha generado; ${ }^{69}$ contrario a ello, en el derecho latinoamericano no se encuentra la misma respuesta, toda vez que allí es posible incluir las normas de conflicto que llevaron a la aplicación de tal derecho extranjero.

Un ejemplo de lo anterior le encontramos en el artículo 2o. de la Ley Venezolana, que indica: "El derecho extranjero que resulte competente se aplicará de acuerdo con los principios que rijan en el país extranjero respectivo, y de manera que se realicen los objetivos perseguidos por las normas venezolanas de conflicto"; en igual sentido que el artículo 82 de la Ley Dominicana, el artículo 7o. de la Convención de Montevideo de 1979 y el artículo 2596 de la Ley Argentina, entre otros.

\section{Prueba de la ley extranjera}

Cuando la norma jurídica conflictual ha determinado que la regla extranjera es la aplicable a la situación en concreto, es lógico estimar que tal precepto elegido será el material, ya que ésa es una de las particularidades inherentes a la naturaleza jurídica del derecho extranjero aplicable, y es que el mismo se convierte en el material y no el conflictual. ${ }^{70}$

En ese sentido, la nueva Ley China, al igual que muchos de los derechos procesales internaciones, determina no sólo la aplicación de oficio del derecho extranjero ${ }^{71}$ por parte de los tribunales, sino que admite que las partes pueden aportar el tenor de la ley que pretenden hace valer en el litigio. En ese sentido la carga de la prueba de una ley extranjera corresponde a la par-

69 Artículo 9o.

70 Arellano García, Carlos, "Nuevas normas sobre la aplicación del derecho extranjero", Revista Jurídica, México, 1991, p. 75.

71 Artículo 10. "El derecho extranjero aplicable a relaciones civiles con elementos de extranjería será aplicado por la Corte Popular, las autoridades arbitrales o los órganos administrativos. Si las partes eligieran el derecho extranjero como aplicable, éste deberá ser probado. Las leyes de la República Popular de China serán aplicables si el derecho extranjero no pudiera ser probado o si no existieran disposiciones aplicables en la ley foránea”. 
Esta revista forma parte del acervo de la Biblioteca Jurídica Virtual del Instituto de Investigaciones Jurídicas de la UNAM

te que quiera obtener provecho de la misma $;{ }^{72}$ desarrollando el conocido principio del actor incumbit probatio que también es acogido en el derecho chino para esta clase de pruebas.

En el ámbito latinoamericano, tenemos al respecto un instrumento normativo unificado, la Convención Interamericana sobre la prueba e información acerca del derecho extranjero de 1979, hecha en Montevideo, Uruguay, que define los parámetros bajo los cuales se puede acceder a un derecho extranjero que se hace necesario para brindar la solución a un litigio internacional. Lo anterior es un complemento a las disposiciones del Código de Bustamante, el cual se inclina por la misma solución, tanto para la aplicación de oficio ${ }^{73}$ como a solicitud de parte ${ }^{74}$ de una ley o derecho extranjero. En igual sentido la Ley Dominicana, ${ }^{75}$ la Argentina, ${ }^{76}$ la Venezolana, ${ }^{77}$ la Panameña, ${ }^{78}$ entre otras.

\section{La residencia habitual como factor de conexión}

Uno de los elementos característicos de la nueva Ley China es que al adoptar las posturas modernas del derecho internacional privado realiza un cambio en el factor de conexión; esto es, para las cuestiones con elementos de extranjería, desplaza el factor de la nacionalidad y el del domicilio por el de residencia habitual, la cual se adquiere o configura después de que una persona ha permanecido, al menos durante un año, en dicho lugar. Si se trata de una persona jurídica, para la cuestión del domicilio se tendrá únicamente en cuenta el lugar de su registro, el cual determinará su nacionalidad. ${ }^{79}$ Lo

72 Véase la sentencia de la Corte de Casación Francesa 16 de noviembre de 1993 caso Amerford Contra Airfrance.

73 Artículo 408. Los jueces y tribunales de cada Estado contratante aplicarán de oficio, cuando proceda, las leyes de los demás sin perjuicio de los medios probatorios a que este capítulo se refiere.

74 Artículo 409. La parte que invoque la aplicación del derecho de cualquier Estado contratante en uno de los otros, o disienta de ella, podrá justificar su texto, vigencia y sentido, mediante certificación de dos abogados en ejercicio en el país de cuya legislación se trate, que deberá presentarse debidamente legalizada.

75 Artículo 82.

76 Artículo 2595.

77 Artículo 2o.

78 Artículos 167 y 168.

79 Zhang, Mo, op.cit., p. 133. 
Esta revista forma parte del acervo de la Biblioteca Jurídica Virtual del Instituto de Investigaciones Jurídicas de la UNAM

anterior es bastante curioso teniendo en cuenta que si algo ha caracterizado al pueblo chino es el arraigo que existe no sólo por su cultura, sino por la nacionalidad; pero la misma como factor de conexión no ha tenido en China la importancia que se le ha dado en otros países que fueron influenciados por las doctrinas de Pasquale Estanislao Mancini, quien tenía en su teoría de la personalidad del derecho uno de sus mayores derroteros, al igual como se acentúa en el artículo 3o. del Código Civil Francés (Código Napoleón). En China se tiene en el domicilio (residencia habitual) el principal factor de conexión en cuestiones relacionadas con el estatuto personal, ${ }^{80}$ así como para determinar los derechos y obligaciones de las personas jurídicas.

De hecho es tanta la importancia que le han dado a la residencia habitual como factor de conexión en la nueva Ley China, que ésta aplica a las cuestiones como: la capacidad civil (matrimonio, familia, sucesiones), ${ }^{81}$ la de ejercicio, ${ }^{82}$ la declaratoria de ausencia o muerte presunta ${ }^{83}$ y los derechos de la personalidad. ${ }^{84}$ Ahora, si la persona a quien debe determinársele su nacionalidad como factor de conexión, tiene múltiples nacionalidades, y tal situación ha de regularse por la Ley China, entonces se regirá

por la ley del país en donde la persona tuviera su residencia habitual. Si no se encontrara la residencia habitual en alguno de los países de los que la persona fuera nacional, el derecho del país con el que la persona estuviera más vinculada será el aplicable. Cuando la persona física sea apátrida o su nacionalidad fuera desconocida, aplicará la ley del lugar de su residencia habitual. ${ }^{85}$

En cuestiones sobre el derecho de las personas jurídicas, el factor de conexión será no sólo la ley del lugar donde éstas se hayan registrado, sino también aquella donde la persona jurídica lleve a cabo su actividad principal o que sea el centro de sus negocios. ${ }^{86}$ En materia contractual, especialmente

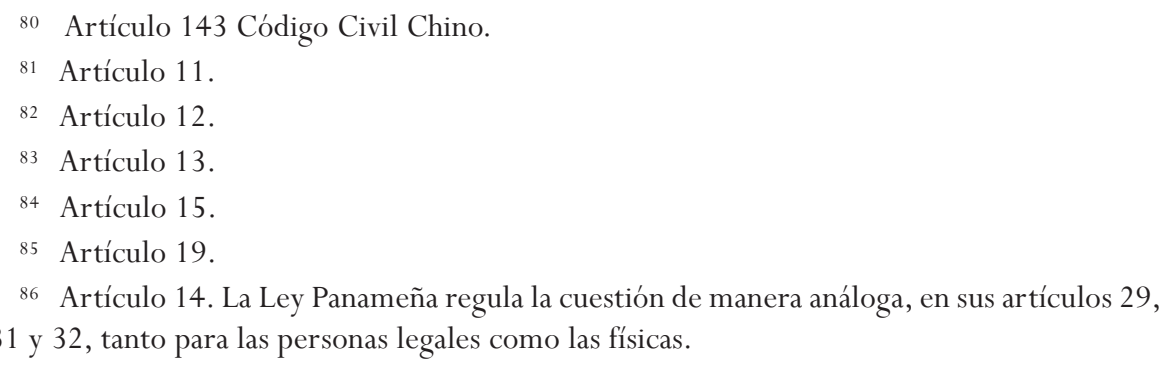


Esta revista forma parte del acervo de la Biblioteca Jurídica Virtual del Instituto de Investigaciones Jurídicas de la UNAM

en los contratos de agencia, ${ }^{87}$ de fideicomisos $(\text { trusts })^{88}$ tal factor lo determinará la ley del lugar de celebración de los mismos.

Por otro lado, lo relativo a la aplicación del factor de la residencia habitual es bastante común en el derecho convencional o uniforme, especialmente en varias de las convenciones de La Haya sobre materias relacionadas con el estatuto familiar, ${ }^{89}$ así como en algunas interamericanas. ${ }^{90}$ En tal sentido, el Código de Bustamante, en su artículo 7o., no señaló precisamente como factor de conexión directa al domicilio o la residencia habitual; en su lugar dejó abierta la posibilidad de aplicar tanto la ley nacional como la del domicilio. En otros de los derechos latinoamericanos que regulan la temática se usa indistintamente el término "residencia habitual" para hablar de domicilio y viceversa. ${ }^{91}$

\section{Estructura de las normas de derecho internacional privado}

\section{A. El matrimonio y sus efectos}

En China, la regulación de cuestiones relativas al matrimonio, como son la capacidad de las partes para celebrarlo y las formalidades que deben observarse respecto al mismo, se halla sometida a un sinnúmero de opciones en cuanto al derecho aplicable a las mismas y que bien puede ser en relación a las partes el de la residencia habitual, o el de la nacionalidad; igualmente el del lugar de celebración de los actos [locus regit actum]. Lo anterior encuentra asidero en el artículo 21, el cual señala que:

87 Artículo 16.

88 Artículo 17.

89 Artículo 4o. del Convenio sobre Ley Aplicable a las Obligaciones Alimenticias de 1977, el artículo 4o. del Convenio sobre la Ley Aplicable a los Regímenes Matrimoniales, artículo 3o. de la Convención sobre la Ley Aplicable a las Sucesiones por Causa de Muerte entre Otros.

90 Artículo 1o. del Tratado de Derecho Civil Internacional y el Tratado de Derecho Comercial Internacional de 1989. Artículo 6o. de la Convención Interamericana sobre obligaciones alimentarias de 1989 hecha en Montevideo.

91 La Ley Venezolana en su artículo 11 señala que: "El domicilio de una persona física se encuentra en el territorio del Estado donde tiene su residencia habitual”, en igual sentido el artículo 5o. y 6o. de la Ley Dominicana, el artículo 2608 de la Ley Argentina, artículo 29 de la Ley Panameña. 
Esta revista forma parte del acervo de la Biblioteca Jurídica Virtual del Instituto de Investigaciones Jurídicas de la UNAM

La capacidad matrimonial será regida por el derecho del lugar donde las partes tengan su residencia habitual común. Si no existiera dicha residencia habitual, la ley de la nacionalidad común será la aplicable. Si no existiera nacionalidad común, la ley del lugar donde se celebre el matrimonio será la aplicable, cuando el matrimonio fuera celebrado en el lugar de la residencia habitual de una de las partes o bien en el país del cual una de las partes sea nacional.

Igual principio aplica para las formalidades respecto a tal matrimonio. ${ }^{92}$ Lo anterior es novedoso ya que el juez dispone de varios recursos en cuanto a la identificación del derecho que considere que más se ajusta a la situación jurídica, lo que evita que se produzca una denegación de justicia.

El caso latinoamericano no es tan amplio como el chino, pues la mayoría de los países que suscribieron el Código de Bustamante o adoptaron el de Napoleón en primer lugar tienen como principio esencial que todo lo relativo a la capacidad se debe regular por la ley nacional ${ }^{93}$ de las partes. La Convención de Montevideo de 1989, ${ }^{94}$ así como las normativas modernas no siguen tal tendencia y, quizás, se inclinan más por la solución adoptada en China debido a que tales cuestiones se regulan por la ley de la residencia habitual ${ }^{95}$ con excepción de la Ley Panameña que sigue dicho criterio, esto es, el de la nacionalidad. ${ }^{96}$

Con relación a la ley que regula los actos sucede lo mismo, ya que si bien la nueva Ley China brinda 3 opciones para determinarla - lugar de celebración, residencia habitual y nacionalidad-, en el caso latinoamericano prima el principio del locus regit actum. Ahora, en cuanto a los deberes y obligaciones de los cónyuges, éstos se regulan tanto en China ${ }^{97}$ como en Latinoamérica ${ }^{98}$ por la ley del domicilio o la residencia habitual de aquellos

92 Artículo 22, nueva Ley China.

93 Artículo 27 y 36 del Código de Bustamante. Código Civil Colombiano artículo 19.

94 Tratado de Derecho Civil Internacional, Artículo 1o. y 11.

95 Artículo 2622 de la Ley Argentina, artículo 31 de la Ley Dominicana, artículo 16 de la Ley Venezolana.

96 Artículo 26.

97 Artículo 23, nueva Ley China.

98 Artículo 12 Convención de Montevideo de 1989, artículo 2624 de la Ley Argentina, artículo 42 de la Ley Dominicana, artículo 22 de la Ley Venezolana y artículo de la 41 Ley Panameña. 
Esta revista forma parte del acervo de la Biblioteca Jurídica Virtual del Instituto de Investigaciones Jurídicas de la UNAM

salvo algunas excepciones, como la que presenta el Código de Bustamante que acoge el criterio de la ley nacional o personal de los cónyuges. ${ }^{99}$

En tal sentido, respecto a los efectos patrimoniales que produce el contrato matrimonial como acto jurídico de naturaleza convencional, los mismos, de acuerdo a la nueva Ley China, podrán ser regulados por el derecho al que las partes los quieran someter, pudiendo ser el de su residencia habitual, el de la nacionalidad de uno de los cónyuges o aun por el derecho del lugar donde estén ubicados los bienes principales — lex rei sitae —; ahora si ninguno de los anteriores se puede establecer, entonces podrá el juez de oficio aplicar la ley de la residencia habitual de ambos y, a falta de ésta, la de la nacionalidad en común. ${ }^{100}$

El derecho latinoamericano no es tan prolífico en opciones en cuanto al derecho aplicable a los efectos patrimoniales del matrimonio; en nuestro caso, tales efectos se rigen esencialmente por la ley del domicilio conyugal. ${ }^{101} \mathrm{El}$ derecho argentino sobre la materia se acerca a la postura del derecho chino al señalar que: "Las convenciones matrimoniales rigen las relaciones de los esposos respecto de los bienes. Las convenciones celebradas con anterioridad al matrimonio se rigen por el derecho del primer domicilio conyugal; las posteriores se rigen por el derecho del domicilio conyugal al momento de su celebración". ${ }^{102}$ Ahora, el derecho panameño somete dicho régimen a la voluntad de las partes, esto es, se aplicará el derecho que las mismas quieran escoger para regular tal situación, ${ }^{103}$ cuestión muy cercana también al derecho chino.

En el caso de las obligaciones y derechos existentes entre padres e hijos, en especial las alimentarias, la tutela y la curatela, las mismas encuentran en el derecho conflictual chino una regulación que adopta un principio general, el de la protección a la parte más débil. En este evento, dicha cuestión puede ser dirigida tanto por la ley de la residencia habitual de ambos como por la de uno de ellos, o la de su nacionalidad, siempre y cuando la normativa seleccionada ofrezca el nivel de protección buscado. ${ }^{104}$ Como bien se

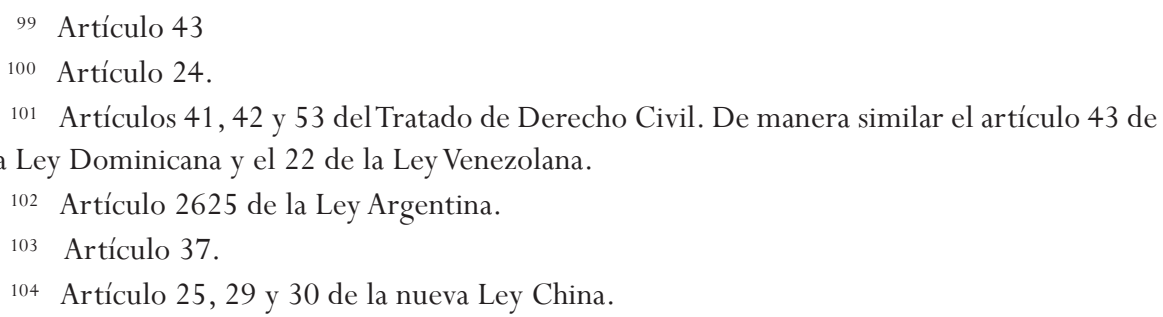


Esta revista forma parte del acervo de la Biblioteca Jurídica Virtual del Instituto de Investigaciones Jurídicas de la UNAM

sabe, las relaciones entre padres e hijos en la cultura china están muy ligadas a la tradición confucianista que ha propendido por que en tales vínculos siempre exista un nivel alto de obediencia y respeto, lo cual se continúa observando en cuanto a su regulación interna.

Ahora, cuando aparece un elemento extranjero en las relaciones personales, la cuestión cambia y ya no tiene prevalencia el derecho nacional o tradicional, sino que hay una adaptación al derecho de la residencia habitual, el cual puede estar en mejor posición para brindar una solución acorde con las realidades internacionales. Desde el punto de vista del derecho latinoamericano, las obligaciones entre padres e hijos se encuentran en una postura intermedia; en efecto, encontramos que el Código de Bustamante somete la cuestión de los alimentos a la Ley Nacional del Alimentado, ${ }^{105}$ en tanto que en instrumentos normativos como la Convención sobre la obtención de alimentos en el extranjero de Nueva York (1956) permite que se acuda al derecho interno (nacional) como al convencional. ${ }^{106}$

Por otro lado, la Convención Interamericana sobre obligaciones alimentarias de Montevideo (1989) se inclina, al igual que el derecho chino, por la postura de la parte más débil de la relación; al efecto indica que:

Las obligaciones alimentarias, así como las calidades de acreedor y de deudor de alimentos, se regularán por aquel de los siguientes órdenes jurídicos que, a juicio de la autoridad competente, resultare más favorable al interés del acreedor:

a) El ordenamiento jurídico del Estado del domicilio o de la residencia habitual del acreedor;

b) El ordenamiento jurídico del Estado del domicilio o de la residencia habitual del deudor. ${ }^{107}$

Por su parte la Ley Argentina, ${ }^{108}$ la Venezolana, ${ }^{109}$ la Dominicana ${ }^{110}$ y la Panameña ${ }^{111}$ siguen el mismo criterio general, el del domicilio o residencia habitual del hijo.

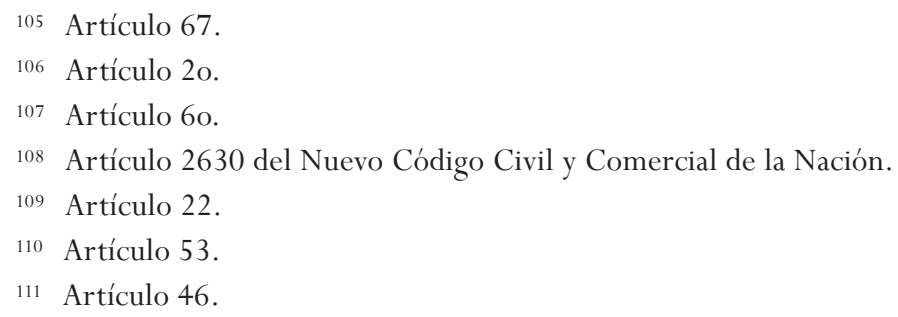


Esta revista forma parte del acervo de la Biblioteca Jurídica Virtual del Instituto de Investigaciones Jurídicas de la UNAM

Respecto al tema del divorcio, el nuevo derecho conflictual chino acude a una amplia gama de opciones en cuanto a la selección que ha de presentarse respecto al derecho aplicable al mismo. En este evento se tendrá en cuenta en primer lugar la autonomía de la voluntad de las partes, al permitirles seleccionar el derecho aplicable al mismo cuando éste se va a llevar a cabo de manera voluntaria y en cuyo caso podrá ser el de la residencia habitual, o el de la nacionalidad de uno de los cónyuges; a falta de dicha elección, será el del domicilio común; si el mismo no existiere, el de la nacionalidad de las partes, y si éste último falla, se aplicará la ley del lugar donde se encuentre el organismo encargado de llevar a cabo tal divorcio. ${ }^{112}$ Ahora en caso de que el divorcio sea contencioso, se sigue un criterio general y es aquél en el que prima la ley del tribunal que conoce del mismo, es decir, el forum loci actus.

Del lado latinoamericano las cosas no son muy diferentes, ya que todas las opciones que presenta el derecho conflictual chino encuentran asidero en sus normativas, aunque no de una forma tan general y amplia. Igualmente, no se encuentra referencia al concepto de "una de las partes" ${ }^{113}$ como sucede en el derecho chino, sino que aquí la elección deber ser de consuno, esto es, de ambas partes y no de una sola. Al respecto podemos traer a colación lo dictaminado por la Ley Dominicana en torno al asunto; la misma preceptúa de manera novedosa que:

Los cónyuges podrán convenir por escrito, antes o durante el matrimonio, en designar la ley aplicable al divorcio ya la separación judicial, siempre que sea una de las siguientes leyes:

1) La ley del Estado en que los cónyuges tengan su residencia habitual en el momento de la celebración del convenio;

2) La ley del Estado del último lugar del domicilio conyugal, siempre que uno de ellos aún resida allí en el momento en que se celebre el convenio;

3) La ley del Estado cuya nacionalidad tenga uno de los cónyuges en el momento en que se celebre el convenio, o

4) La ley dominicana siempre que los tribunales dominicanos sean competentes.

112 Artículo 26 de la nueva Ley China.

113 La Ley Venezolana tiene un criterio similar que el derecho conflictual chino al definir en su artículo 23 que: "El divorcio y la separación de cuerpos se rigen por el derecho del domicilio del cónyuge que intenta la demanda”. 
Esta revista forma parte del acervo de la Biblioteca Jurídica Virtual del Instituto de Investigaciones Jurídicas de la UNAM

Ahora, en un sentido que se acoge a una de dichas posturas, tenemos al Tratado de Montevideo, ${ }^{114}$ así como a la Ley Panameña, que son del criterio que el derecho aplicable a tales cuestiones debe ser básicamente el del domicilio conyugal. ${ }^{115}$

Con relación al tema de la adopción internacional, el derecho conflictual chino, al igual que el latinoamericano, sigue una línea similar con relación a la ley aplicable a la misma, ya que para el primero aquélla será la de la residencia habitual, mientras que para el segundo, la del domicilio, tanto para las cuestiones sobre la capacidad del adoptante como para la protección del menor adoptado. ${ }^{116}$

\section{B. Derecho sucesoral}

En cuanto al tema de las sucesiones, en el derecho conflictual chino participa de una línea que es bastante universal en cuanto a la ley aplicable a las mismas, el principio de la lex rei sitae para la regulación tanto de los bienes muebles ${ }^{117}$ como los inmuebles. ${ }^{118}$ En materia de testamentos se acoge la conocida regla del locus regit actum para dotar de validez a ciertos actos jurídicos; ambos criterios, es decir, tanto el de los bienes como el de los actos jurídicos, van ligados al de la ley de la residencia habitual del causante como la del testador. Por su parte, en el derecho latinoamericano no vemos muchas diferencias, ya que tienen igualmente aplicación los principios ante-

114 Artículo 13.

115 Idem.

116 Artículo 28 de la nueva Ley China. De la misma manera la Convención Interamericana sobre conflictos de leyes en materia de adopción de menores. La Paz (1984). Acoge tanto el principio de la residencia habitual, como el del domicilio en sus artículos 3o. y 4o. para regular lo relativo a las adopciones internacionales. En ese sentido, la Convención de La Haya de 1993, relativo a la protección del niño y a la cooperación en materia de adopción internacional, también somete dicha regulación a la residencia habitual, ello lo encontramos en el artículo 14. Por su parte el artículo 2636 de la Ley Argentina, el artículo 25 de la Ley Venezolana, el artículo 47 de la Ley Panameña. La Ley Dominicana es la excepción ya que somete la adopción a la ley nacional si éste se lleva a cabo en la República Dominicana o a la de la residencia del adoptante o el adoptado en cuanto al consentimiento (Artículo 50); también adoptando el criterio de la ley nacional tenemos al Código de Bustamante en sus artículos 73, 74 y 75 .

117 Nueva Ley China, artículos 34 y 35.

118 Ibidem, artículo 31. 
Esta revista forma parte del acervo de la Biblioteca Jurídica Virtual del Instituto de Investigaciones Jurídicas de la UNAM

riormente enunciados; ello lo encontramos en el Tratado de Montevideo de $1989,{ }^{119}$ en la Ley Argentina ${ }^{120}$ en la Dominicana, ${ }^{121}$ en la Panameña ${ }^{122}$ y en la Venezolana. ${ }^{123}$ En materia de testamentos, la excepción la pone el Código Bustamante en sus artículos 146 y siguientes, en los que tiene primacía la ley nacional del testador, incluso en cuanto a la forma del mismo.

\section{Derecho de los bienes}

Con relación al manejo que se le da al punto de los bienes en el derecho conflictual chino, podemos observar que allí también se acoge un principio muy universal en cuanto a la ley que ha de regular las situaciones jurídicas que estén relacionadas con éstos en sus clasificaciones de muebles e inmuebles; por eso, al igual que como ocurre en el derecho sucesoral, éstos estarán sometidos a la ley de su situación, ${ }^{124}$ esto es, a la lex rei sitae.

Ahora, como novedad encontramos que en el derecho chino se permite a las partes que, cuando se trate de llevar a cabo relaciones jurídicas que impliquen a los bienes muebles, puedan escoger el derecho aplicable a los mismos; ${ }^{125}$ en este caso habrá que analizar si al aplicar una ley extranjera que regula la situación de tales bienes, ésta remite a otro derecho, en cuyo caso haría inaplicables las normas de conflicto de leyes chinas. En cuanto a los actos jurídicos que estén en relación directa con bienes, dichos actos siguen siendo regulados por la ley del lugar donde se lleven a cabo, esto es, bajo el principio del locus regit actum, ${ }^{126}$ en cuyo caso prima la categoría de acto jurídico sobre la de bien.

En el derecho latinoamericano, como quedo arriba señalado, se acogen igualmente tales principios; en especial el del derecho del lugar donde se encuentran situados los bienes; ${ }^{127}$ no sin antes señalar que también se pre-

119 Artículos 26, 32, 44 y 46.

120 Artículos 2644 y 2645

121 Artículo 54.

122 Artículo 57.

123 Artículos 34 y 37.

124 Nueva Ley China, artículo 36.

125 Ibidem, artículo 37.

126 Ibidem, artículos 39 y 40.

127 Tratado de Montevideo de 1989, artículo 26. Código de Bustamante, artículo 15. Ley Argentina, artículo 2667. Ley Dominicana, artículo 76. Ley Panameña, artículos 65 y siguientes. Ley Venezolana, artículo 27. 
Esta revista forma parte del acervo de la Biblioteca Jurídica Virtual del Instituto de Investigaciones Jurídicas de la UNAM

sentan ciertas excepciones y una de ellas la aporta la Ley Argentina que somete los bienes muebles que son susceptibles de registro a la ley del lugar donde se lleva a cabo tal acto; lo que en cierta medida conlleva a que se prescinda de la ley, para adaptar la situación a la de la celebración de tal acto de protección. ${ }^{128}$

\section{Obligaciones contractuales}

Así, al igual que como sucede con la cuestión de los bienes, en materia de obligaciones que nacen de la autonomía de la voluntad de las partes, encontramos en el nuevo derecho conflictual chino una pauta muy similar a la se emplea en la mayoría de los derechos uniformes latinoamericanos que regulan los conflictos de leyes, y es el hecho de que tales situaciones se someten esencialmente a la ley escogida por las partes para regular su relación obligacional. La nueva Ley China, en este caso, está bastante inspirada en el Convenio de Roma de 1980 sobre el derecho aplicable a las obligaciones contractuales (en el caso latinoamericano, la Convención Interamericana sobre el derecho aplicable a los contratos internacionales, México, 1994, artículo 7o.), la cual en su artículo 3o. aborda el tema de forma sistemática; incluyendo en su artículo 4o. el concepto de los "vínculos más estrechos", que también es retomado tanto por el derecho chino ${ }^{129}$ como por la Convención de México. ${ }^{130}$ Sin embargo, el derecho chino acude a otro criterio para regular tal situación, aquel que se utiliza en la mayoría de la ley, el de la residencia habitual de la parte que lleva a cabo la prestación característica. ${ }^{131}$

Ahora, se ha de tener presente que en cuestiones como los contratos con los consumidores o con los trabajadores, quienes en cierta medida son tenidos como las partes débiles de una relación contractual, el derecho conflictual chino se ha inclinado, en primer lugar, por la protección que le ofrece a dicha parte el derecho de su residencia habitual, así como el derecho de lugar donde se realiza la labor para los contratos laborales. En tanto, en caso de que no fuese posible determinar dicha ley, se deberá acudir a donde el

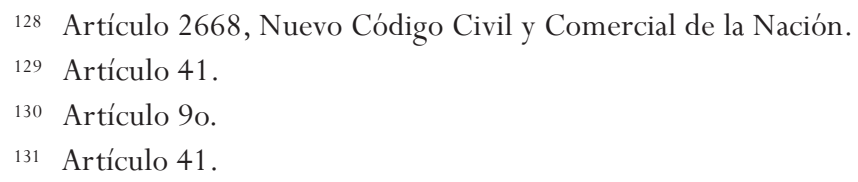


Esta revista forma parte del acervo de la Biblioteca Jurídica Virtual del Instituto de Investigaciones Jurídicas de la UNAM

consumidor realizó la compra, ${ }^{132}$ o donde se encuentra el establecimiento principal del jefe del trabajador. ${ }^{133}$

En América Latina, la ley Dominicana, ${ }^{134}$ la Panameña ${ }^{135}$ y la Venezola$\mathrm{na}^{136}$ abordan esos asuntos en términos muy similares al derecho conflictual chino, en especial lo relativo a la ley escogida por las partes, así como a la que presente los vínculos más estrechos con el contrato en ausencia de escogencia de la misma.

\section{E. Responsabilidad extracontractual}

En el derecho chino, en materia de responsabilidad civil extracontractual, al igual que sucede en el derecho comparado, se utiliza el mismo principio para determinar, en primer lugar, la ley aplicable a los hechos que produjeron alguna clase de daño, aquel de la lex loci delicti; sin embargo, como sucede en gran parte de la nueva Ley China, éste no es el único criterio que se utiliza para determinar el derecho aplicable a aquel tipo de situaciones; en tal determinación se incluyen igualmente reglas tales como la residencia habitual común de las partes implicadas; incluso podría aplicarse una ley que haya sido escogida posteriormente por las mismas partes. ${ }^{137}$

En el derecho latinoamericano, la Ley Dominicana, en torno a los daños derivados de la responsabilidad contractual, define un principio bastante cercano al chino y es aquel que establece en su artículo $69,{ }^{138}$ que señala que las partes puedes escoger la ley aplicable a dicha responsabilidad, esto es, la elegida por las partes o la del lugar donde ocurrió el daño.

Si la responsabilidad proviene de la utilización de productos defectuosos, la misma, de acuerdo al derecho conflictual chino, podrá ser regulada de

132 Artículo 42. Artículo 2655 de la Ley Argentina. El derecho panameño somete los contratos con los consumidores a al principio del locus regit actum; en cuyo caso el contrato se regulará por la ley del lugar en donde fue concluido.

133 Artículo 43. De manera similar el artículo 62 de la Ley Dominicana; La ley Panameña en su artículo 94 somete los contratos laborales a la ley de cumplimiento de la obligación - lex loci executionis — , a falta de ésta, a la ley del establecimiento principal del empleador.

134 Artículo 58 y 60.

135 Artículo 74 y 77.

136 Artículo 29 y 30.

137 Artículo 44.

138 Para la Ley Venezolana rigen los criterios de la lex loci delicti commisi et damni. Artículo 32. 
Esta revista forma parte del acervo de la Biblioteca Jurídica Virtual del Instituto de Investigaciones Jurídicas de la UNAM

manera muy amplia tanto por la ley de la residencia habitual de la parte afectada ${ }^{139}$ como por la ley del establecimiento principal del infractor, o la del lugar donde se produjo el hecho dañoso. ${ }^{140}$ Ahora, respecto a la responsabilidad derivada de mala gestión de los negocios, al pago de lo no debido y al enriquecimiento sin causa, éstos se regularan en el derecho conflictual chino por el derecho elegido por las partes, a falta de éste, el de la residencia habitual de las partes, o en su defecto por el derecho del lugar en el cual se llevan a cabo dichos actos. ${ }^{141}$

\section{REFLEXIONES FINALES}

La promulgación de la Ley de la República Popular de China sobre las leyes aplicables a las relaciones civiles con elementos de extranjería por parte del presidente Hu Jintao marcó un hito en el derecho internacional privado, toda vez que aquel país está llamado a convertirse en la potencia por excelencia en los años a venir, lo cual no es gratuito y le da el impulso necesario a una ciencia que cada vez reclama más su espacio en el contexto mundial del derecho.

Como se ha podido advertir, tal ley se elabora a partir no sólo de conceptos propios, sino de diferentes sistemas jurídicos occidentales, lo que muestra la intención de China de integrase a la globalidad y comenzar a hablar esa lingua franca que representa el derecho internacional en las relaciones interpersonales que se dan actualmente en la sociedad global.

Por otro lado, en cuanto a su contenido, la Ley China no se distancia mucho de las posturas del derecho latinoamericano en la materia, puede decirse que incluso lo complementa en algunos aspectos, e incluso podemos apreciar que, frente a normativas como el Código de Bustamante, lo supera en cuanto a las opciones que brinda para hallar la ley aplicable a un determinado litigio, de una manera más precisa y concisa.

139 Este mismo criterio aplica cuando la vulneración de los derechos tanto a la privacidad como de la imagen, la honra y el nombre se ha producido de manera virtual en la Internet. Artículo 46.

140 Artículo 45.

141 Artículo 47. En el caso de la Ley Venezolana, se aplica únicamente el criterio del "Derecho del lugar en el cual se realiza el hecho originario de la obligación". Artículo 33. 
Esta revista forma parte del acervo de la Biblioteca Jurídica Virtual del Instituto de Investigaciones Jurídicas de la UNAM

Si bien no se trata de una verdadera codificación de derecho internacional, ya que sólo se aborda en esencia la cuestión de los conflictos de leyes, la misma se convierte en un elemento valioso para propender por un mejor acercamiento entre China y el resto de los sistemas jurídicos que regulan tales cuestiones.

En este sentido, es curioso ver como en la nueva Ley China, el factor de la nacionalidad se ubica en un segundo lugar para darle paso a la residencia habitual; decimos esto porque si algo tenemos claro los occidentales es que en China la nacionalidad forma parte del alma de dicho pueblo, pues ha sido defendida a capa y espada durante siglos; sin embargo, ésta ha sido relegada a un segundo plano para poder adaptarse a los requerimientos que nos muestra la globalización hoy en día, lo que indica también un cierto deseo de flexibilización por parte del pueblo chino.

La Ley tiene una estructura bastante occidental tomada del modelo alemán o pandectista, el cual se basa esencialmente en una parte general precedida por capítulos que desarrollan temas específicos; sin embargo ésta acude a figuras que desarrolla en casi todo el texto, como el principio de proximidad (los vínculos más estrechos), la libertad de las partes de escoger la ley que regulará su contrato (libertad contractual), la prevalencia de la residencia habitual y la protección de la parte más débil en una relación contractual, lo cual le da un aire no sólo más moderno, sino adaptable a las necesidades modernas en cuanto a la materia.

Ahora, en respuesta a los interrogantes iniciales, podemos afirmar que desde el punto de vista comparativo con el derecho internacional privado latinoamericano, creemos que no es mucha la diferencia existente entre ambos, es decir, entre el derecho conflictual chino y las diferentes leyes que sobre la materia han sido promulgadas en varios países y entre los proyectos de ley que están por ver la luz, como el de México, Uruguay, Colombia, entre otros. Como lo hemos visto, hay muchas coincidencias entre las diferentes normativas, pero lo que quizás más nos llama la atención del derecho chino es la amplia gama de opciones que tiene el juez o el operador jurídico para determinar la ley aplicable a un determinado caso, lo cual se da poco en los derechos nuestros, los cuales, en muchas ocasiones, son bastante limitados al respecto. Sin embargo podemos apreciar que entre ambos sistemas jurídicos (el "latinoamericano" tomado en conjunto y quizás como una ficción, ya que no existe como tal) se presenta una cercanía que hace que esta clase de derecho sea más global y unificado en sus criterios. 
Esta revista forma parte del acervo de la Biblioteca Jurídica Virtual del Instituto de Investigaciones Jurídicas de la UNAM

De igual manera, es posible tener un acercamiento entre dichas culturas jurídicas, ya que ambas están mirando en una misma dirección al movimiento global, especialmente en cuanto a lo que tiene que ver con la cuestión económica, en la que lo jurídico es imprescindible para dar firmeza a las miles de transacciones que día a día se llevan a cabo entre ambos territorios; en segundo lugar está lo relativo a las cuestiones personales, lo cual no es menos importante, sabiendo que el intercambio económico necesariamente conlleva el movimiento transfronterizo de personas con las vicisitudes que aquello también implica.

\section{BIBLIOGRAFÍA}

Arellano García, Carlos, "Nuevas normas sobre la aplicación del derecho extranjero”, Revista Jurídica, México, 1991.

Código de Hammurabi, introducción de Azpiri, Jorge O., Buenos Aires, 2010. BEECHING, Jack, La guerra del opio, trad. de Álvaro Castillo, Barcelona, Plaza \& Janés, S.A. Editores, 1976.

CARRASCOSA GONZÁLEZ, Javier, "Las primeras normas de conflicto escritas de la Historia. Bolonia, Murcia y Jacobo de las Leyes", septiembre-noviembre de 2016, disponible en: http: / / accursio.com/blog/?p=120.

Cesarín, Sergio M., "Ejes y estrategias del desarrollo económico chino: enfoques para América Latina y el Caribe”, China y América Latina. Nuevos Enfoques sobre Cooperación y desarrollo. ¿Una segunda ruta de seda?, Buenos Aires, Red de Centros de Estudios de Asia y el Pacífico de América Latina y El Caribe, 2005.

DENG, Pan, "El panorama legislativo del derecho internacional privado chino tras la publicación de la nueva ley para la determinación de la ley aplicable a las relaciones con los extranjeros en materia civil”, Revista Jurídica. Universidad Autónoma de Madrid, Madrid, núm. 29, 2014-I.

Dupla Marín, María Teresa, "La recepción del derecho romano en el movimiento de unificación del derecho privado y la Constitución europea”, septiembre-noviembre de 2016, disponible en: http: / / ruc.udc.es/bitstream / 2183/2225/1/AD-7-14.pdf. 
Esta revista forma parte del acervo de la Biblioteca Jurídica Virtual del Instituto de Investigaciones Jurídicas de la UNAM

FERnÁndez Rozas, José Carlos, El Código de Napoleón y su influencia en América Latina: Reflexiones a propósito del segundo centenario, Mérida, SABER ULA-Universidad de los Andes, 2006.

Fundación Biblioteca Ayacucho, septiembre-noviembre de 2016, disponible en: http: / / www.bibliotecayacucho.gob.ve/fba/index.php?id=21\&tx_ttnews\%5Btt_n ews $\% 5 D=1532 \&$ tx_ttnews\%5BbackPid\%5D $=2 \&$ cHash $=6 a 1$ c818917.

GARRO, Alejandro M., "Armonización y unificación del derecho privado en América Latina: esfuerzos, tendencias y realidades, Revista de la Facultad de Ciencias Jurídicas y Políticas, Caracas, núm. 85, 1992.

Helguera, Enrique, El derecho internacional privado mexicano y el Código de Bustamante, México, UNAM, Instituto de Derecho Comparado, 1962.

HuANG, Jie, "Interregional Recognition and Enforcement of Civil and Commercial Judgements: Lessons for China and US and EU Laws", Journal of Private International Law, vol. 6, núm. 1, 2010, septiembre-noviembre de 2016, disponible en: http://works.bepress.com/jie_huang/4.

HuO, Zhengxin, "An imperfect improvement: the new conflict of laws act of the People's Republic of China", The International and Comparative Law Quarterly, Cambridge, vol. 60, núm. 4, octubre de 2011.

Huo, Zhengxin, "Highlights of China's New Private International Law Act: From the Perspective of Comparative Law", septiembre-noviembre de 2016, disponible en: https: / /ssl.editionsthemis.com/uploaded/revue/article/ 5973_45-3\%20Huo.pdf.

Mesa-Moles Martel, María Paz, Génesis y formación del derecho internacional privado, tesis doctoral, septiembre-noviembre de 2016, p. 22, disponible en: https: / / eciencia.urjc.es/bitstream/handle/10115/1058/TESIS\%20 MESA\%20MOLES.pdf;jsessionid=16C7F8E0CC40EDD17968AC0D98DAB2 $3 F$ ? sequence $=1$.

Nord, Nicolás y Vieira da Costa Cerqueira, Gustavo, "Comments on the Chinese new Statute on Conflict of Laws: A European Perspective", Chinese Yearbook of Private International Law and Comparative Law, vol. 14.

Nova MonReal, Eduardo, Defensa de las nacionalizaciones ante tribunales extranjeros, México, UNAM, Instituto de Investigaciones Jurídicas, 1976.

SiqueIROS, José Luis, "La codificación del derecho internacional privado en el continente americano”, Revista Jurídica, México, núm. 14, 1982.

SOTO VON ARMIN, Laura, "La historia del derecho internacional privado en China y sus fuentes”, Anuario Colombiano de Derecho Internacional, Bogotá, vol. 6, 2013. 
Esta revista forma parte del acervo de la Biblioteca Jurídica Virtual del Instituto de Investigaciones Jurídicas de la UNAM

Yu, Shuhong et al., "The Closest Connection Doctrine in the Conflict of Laws in China", Chinese Journal of International Law, Oxford University Press, vol. 8, núm. 2, 2009.

YANES, Francisco Javier y Mendoza Montilla, Cristóbal, Colección de documentos relativos a la vida pública del Libertador de Colombia y del Perú, Simón Bolívar, para servir a la historia de la independencia de Suramérica, Caracas, t. IV, 1826.

Zhang, Mo, "Codified Choice of Law in China: Rules, Processes and Theoretic Underpinnings", Journal of International Law and Commercial Regulation, Carolina del Norte, vol. 37, núm. 1, 2011.

Zimmerman, James M., A legal Guide to foreing Invested Enterprises, Beijing, American Bar Association, China Law Deskbook, 2010. 